\title{
A Sociopolitical Perspective on the Illegal Take of Wildlife in the Southeastern, USA
}

CHRISTOPHER SERENARI, Ph.D.

Human Dimensions Specialist

North Carolina Wildlife Resources Commission

1751 Varsity Dr.

Raleigh, NC 27606

M. NILS PETERSON

Associate Professor

Department of Forestry and Environmental Resources

Fisheries, Wildlife, and Conservation Biology Program

North Carolina State University

Turner House, Box 7646

Raleigh, NC 27695-7646 USA

Corresponding author: Christopher Serenari: 1-919-707-0057; cserenari@gmail.com

\begin{abstract}
Illegal take of wildlife is a complex and growing phenomenon, influenced by various factors. Scholars have paid limited attention to structural influences, however. We examine the structural processes that influence illegal take behavior in rural areas of the southeastern USA. Engaging historical and contemporary qualitative data from the region, we first identify that struggles between a rural hunting sub-culture and outsiders over the meaning and governance of humanwildlife interactions in rural areas emerged from several sociopolitical shifts. We then associate illegal take behavior performed by the rural hunting sub-culture with a radicalization framework consisting of injustice, vulnerability, superiority, and distrust. Regulators should not be surprised by the occurrence of illegal take behavior because sociopolitical factors contributed to delegitimization of wildlife law among the sub-culture. Engaging sub-culture gatekeepers in ways that limit exclusionary wildlife governance and imposition of external values may moderate negative outcomes caused by major sociopolitical shifts.
\end{abstract}

Keywords: illegal take; law; radicalization; subculture; wildlife 


\section{Introduction}

The illegal take of wildlife is a complex and growing global phenomenon (Eliason 2003b). Often termed poaching, it is influenced by social, cultural, cognitive, and political factors and, depending on one's perception, it is a practice that can blur the boundaries of legitimacy within wildlife governance (von Essen and Allen 2015). Scholars have attempted to unpack this complexity and simplify these boundaries, crafting primarily reductionist typologies, theories, and models to profile offenders (von Essen, Hansen, Källström, Peterson, and Peterson 2014). The foci of these studies tend to be poacher motivations and rationalizations for their behavior (e.g., Eliason 1999; Muth and Bow Jr. 1998). These studies can assist scholars and wildlife managers to "describe, prescribe, predict, and explain" aspects of illegal take behavior and how to address it (Kahler and Gore 2012, p.104). Addressing illegal take behavior in this way is useful for problematizing what is wrong with the individual, but pays insufficient attention to social dynamics contributing to the behavior (von Essen et al 2014).

Deviant subcultures, including those associated with illegal hunting, are not static and isolated from the greater "straight" society (Brymer 1991, p. 178) and scholarship on how the structural or sociopolitical context influences them is scholastically innovative and practically necessary. For instance, the sociopolitical context is critical to understanding illegal hunting behavior because it "has placed what may often be law-abiding hunters in a position from which they can be triggered in the first place" and "thereby induce" normally straight hunters to violate the law (von Essen et al 2014, p. 14). Few studies offer insights on the sociopolitical factors that drive illegal take behavior. As such, a complete understanding of behavioral triggers or how behavior changes when the sociopolitical context changes remains elusive and undertheorized. With a more comprehensive understanding of why hunters engage in the illegal take of wildlife, managers might design more efficient interventions to reduce policy breaches before they have negative biological and social impacts (Pitcher, Watson, Forrest, Valtýsson, and Guénette 2002). Moreover, it may help shift wildlife agency focus from the individual to broader and perhaps unanticipated behavioral drivers, such as environmental or social policies (Bell, Hampshire, and Topalidou 2007), wildlife management agency assumptions about poaching (Enck and Decker 1997), or deeply rooted cultural norms (Grigsby 2011; Fortsyth, Gramling, and Wooddell 1998).

In this study we examined the understudied societal processes of marginalization that influence illegal take of wildlife behavior in rural areas. Focusing on the rural regions of the southern U.S. and employing historical and contemporary wildlife cases from North Carolina, we uncover sociopolitical drivers perceived as threatening a rural hunting subculture. We then sketch a corresponding radicalization trajectory (i.e., deviation from the greater society) from law-abiding citizens to hunters that violate the law, creating a deviant subculture. We conclude with the implications of our results for scholars and practitioners within dynamic social and political climates. We postulate that a rural hunting subculture, which spans but does not include all members of several micro sub-cultures (e.g., still hunters; trophy hunters; pot (subsistence) 
hunters; dog hunters; illegal hunters; legal hunters; slob hunters), exists. We also assume that this sub-culture is a major tenet of rural society in the southeastern U.S., embraces illegal take behavior, and is "in continued contact and negotiation with the dominant cultural world" (Brymer 1991, p.178). This paper focuses broadly on this hunting sub-culture as rural interests struggle against external social and political threats to the ways the former defines the meaning and regulation of rurality (Woods 2006).

\section{Methods}

Between February and April 2013, we used purposive sampling and interviewed sportspersons in North Carolina. Prior to distribution to the targeted sample, we tested the interview instrument by performing cognitive interviews with a convenience sample of 15 sportspersons in North Carolina. We identified study participants who were 18 years of age or older, claimed to have violated a fishing or hunting law, and were living in North Carolina. The sampling frame was obtained from social networks of the authors and upperclassmen in the North Carolina State University Fisheries, Wildlife, and Conservation Biology program because there was no existing frame for participants we sought to interview. Participants ranged from strangers to close friends and family members of student researchers. In an attempt to establish trust with participants (Gavin, Solomon, and Blank 2010), researchers administered in-person questionnaires and presented participants with a letter from the North Carolina Wildlife Resources Commission (WRC) stating that questionnaire responses would not lead to prosecution. We complemented our interviews and addressed issues about bias, precision, and contextualization with data triangulation (Peterson, Peterson, Peterson, Lopez, and Silvy 2002), an approach that incorporates data from different sources, perspectives, and contexts (Reeves, Kuper, and Hodges 2008). This enabled us to cross-check themes and events so that we achieved a more profound and rich interpretation of the data (Altrichter, Feldman, Posch, and Somekh 2013). We achieved triangulation by merging individual interview transcripts, public hearing testimony, consultations with wildlife law enforcement officers, and secondary qualitative data sources on southern hunting culture and practices. We mined secondary qualitative data obtained from audio recordings and documents from public hearings about wildlife management, peerreviewed literature, historical accounts, ProQuest Newsstand database, and the World Wide Web. We employed QSR International's NVivo v.10 qualitative data analysis software (Burlington, MA) to organize interview data and themes. Continual movement between text and themes allowed us to find thematic moments and relationships to build a "thematic map" (Guba and Lincoln 1985) and situate illegal take behavior within a historically informed sociopolitical context. Descriptive statistics were run on interview subjects with IBM SPSS Statistics v.22. In all cases, citizen names were changed. 


\section{Results}

Of the 51 hunters interviewed, ages ranged from 18 years old to 87 years old, while most were white (84\%), male (94\%), and single (63\%). Many (45\%) hailed from a census designated rural area and most (61\%) were from a community with less than 10,000 residents. Although all respondents reported violating hunting laws, few (18\%) reported being cited.

\section{A Politics of the Rural: A Hunting Subculture under Threat}

Analysis of interview data focused our attention on rural geographies. Informants disclosed that some areas in North Carolina were "just rural enough area where (getting caught) is just not something you need to worry about" (Respondent 56), while others provided a Wild West characterization of rural areas in North Carolina, asserting that there "ain't no laws in the country" (Respondent 37). One informant offered the case of Zebulon, a town with a population of about 4,400, located in eastern Wake County, North Carolina.

If you knew more about the town of Zebulon, you would understand because there is honestly not a whole lot that goes on in that town, and a lot of people think it is pretty easy to get away with anything without suffering any consequences or getting caught (Respondent 3 ).

A politics of the rural equates to conflict over the meaning and governance of rurality (Woods 2006). Rural settings exhibit unique socio-ecological characteristics that facilitate the illegal take of wildlife as a way that hunters can retaliate politically (Eliason 2011; Forsyth, Gramling and Wooddell 1998). Economic and social isolation, marginalization, and social decline in the southeastern U.S. provide a social and political backdrop with which rural interests constructed a unique a hunting subculture within the greater societal whole. This subculture has unique norms, networks, and identities to which rural interests will mobilize in order to defend against external threats (e.g., von Essen et al 2015). Factors that portend sociopolitical changes impacting rural cultural landscapes can provide the impetus for rural hunters to illegally take wildlife (von Essen et al 2014), making the subculture a deviant one. Below, we identify sociopolitical forces that have generated potential threats to a rural hunting subculture in regions that are historically dependent on hunting in the southeastern U.S., focusing on North Carolina. These forces provide a foundation with which to explore the theoretical radicalization of a rural hunting subculture in rural parts of the southeastern U.S.

Failed economic revolutions: The failed transition from subsistence economy to postindustrial state in the rural southeastern U.S. kept many rural communities destitute and may contribute to illegal take of wildlife in the region today. This failed transition facilitated the disappearance of rural peoples' hunting institutions (e.g., pot and market hunting, common hunting areas), which were essential to subsistence livelihoods of the $19^{\text {th }}$ and $20^{\text {th }}$ centuries and 
weathering hard times (Mell 1938). Marks (1991, p. 28) chronicled the apex of game use in everyday Carolina residents' lives prior to the Civil War:

All racial and social groups of the antebellum Carolinians were fond of hunting, and game was an important part of most diets throughout the year... wild game of all sorts found its place on the tables of most social groups, and into the marketplace.

Dependence on the land shrunk under the weight of progress. Roebuck and Hickson III (1982, p. 16) summarized land dependence trends over a 35 year period after the Civil War:

In the post bellum period, between 1865 and 1900, the poor whites were integrated into the economic system as one, dependent lumpen lower class. They shifted from small subsistence farming, hunting, fishing, and herding to tenancy and sharecropping, to wage earners as mill workers, miners and factory hands. Most poor whites and blacks became tenants and share croppers in a competitive situation.

Southern poor whites and blacks, in particular, were simply ignored with the aristocracy's installation of plantation economies in the late $17^{\text {th }}$ and $19^{\text {th }}$ centuries, as well as the industrial expansion in the late $19^{\text {th }}$ century (Mell 1938; Flynt 2004), each shift widening gaps between affluent and poor. Negative social outcomes ranged from diminished wages, a surplus of unskilled labor, racial violence (Cobb 1984), and dietary changes resulting in regional health problems (Kirby 2006). North Carolina laborers remained under-educated and under-employed for generations (Flowers 1992), and a sharp decline in the textile industry during the early 2000s compounded poverty issues for rural communities (Coclanis and Kyriakoudes 2007; Keefe 2000).

Government economic stimulus programs targeted poverty during the heights of urbanization and industrialization in the southeastern U.S. in the $20^{\text {th }}$ Century (Ford 1973). Yet, the rural hunting subculture in question continued to rely on hunting during this time (Flynt 2004), as well as more recently when globalization moved jobs and markets out of rural areas and overseas (Keefe 2000). "A vortex of change" (Brymer 1991, p.183) tested and altered values towards wildlife and game law among rural poor in the southeastern. A North Carolina informant interviewed in Marks's Southern Hunting in Black and White (1991, p. 189) provided a rural hunting sub-culture response: "I think if you are poor your values shift, needfully so. If you are hungry enough, you'd trap every quail in Scotland County to put on the table or sell."

The closure of the commons and advent of wildlife law: The closure of the commons, aided by wildlife game law, changed how people and wildlife interacted and redefined livelihoods. 
Hunting and fishing on the open range supported rural southern livelihoods for 200 years prior to the Civil War and was considered a common-use right of rural people (Petty 2013). The advent of stock laws ${ }^{1}$ turned "gleaners...to poachers," outlawing historical access to common pool natural resources for subsistence (Chazkel and Serlin 2010, p.2). The wildlife conservation regulation regime gained traction in the southeastern U.S. during the $19^{\text {th }}$ and $20^{\text {th }}$ centuries and was used by elites to enforce the closure of the commons (Flynt, 2004; Forsyth, Gramling, and Wooddell 1998). A growing network of wealthy and politically influential sportsmen and naturalists, who deplored the cumulative effects of large-scale market wildlife hunting (Marks 1991) and agricultural deforestation (Kirby 2006), successfully wielded enough power to change wildlife and natural resource use laws at all levels of government.

In North Carolina, they were the driving force behind the advent of hunting and fishing licenses, game bills and laws, species designations, and creation of the State Game Commission in 1927 (which became the WRC in 1947) (Marks 1991). The narratives typically provided with descriptions of the "North American Model" of wildlife management (Organ et al 2012) describe the end of market hunting, but omit any mention of the fact that this transition entailed a power shift in which the rural residents were disenfranchised from centuries old livelihoods.

Meanwhile, small woodlot owners, who tended to be poor hunters and fishers, resisted corporate attempts to buy their plots and force them into the booming pulp and paper industry and farmers resisted efforts to terminate forest clearing practices; new forest protection (fire suppression) and wildlife conservation (game) laws infused bitterness among rural populations (Montrie 2011). Despite rural resistance, nearly all North Carolina counties regulated hunting and fishing by 1906 (Kirby 2006).

The wildlife protection movement: Shifting societal values about wildlife and hunting during the antebellum period led to greater imposition from outside wildlife protection groups and their ideas and values into rural areas (e.g., Gilton 2008). The spread of protectionist ideology fostered an "us" versus "them" mentality where rural residents prepared to fight for their ideals and violate wildlife laws. During Reconstruction, elite sportsmen and conservationists sought to end market and subsistence hunting, their actions underscored by racial and class biases (Kirby 2006). For instance, southern hunting historians revealed that poor whites embraced elite hunting norms as a way to separate themselves from blacks after the Civil War, though general sentiment among rural poor was that sport (leisure) hunting and the wildlife conservation movement were unwanted elites projects (Marks 1991; Kirby 2006).

Wolf reintroduction is a contemporary way urban environmental values have imposed upon rural hunters. The reintroduction of the endangered red wolf (Canis rufus) on the Albemarle Peninsula (AP), the U.S. Fish and Wildlife Service's (USFWS) attempt to reintroduce an apex predator onto the landscape, is an exemplary case of wildlife protection groups' values impacting rural realities. Issues surrounding The Red Wolf Recovery Program (RWRP) came to a head in 2014 when the Red Wolf Coalition and Southern Environmental Law Center sued the WRC for 
allowing residents to shoot coyotes (Canis latrans) at night. After numerous cases of alleged mistaken identity, a settlement and federal injunction stopped night hunting of coyotes to prevent the killing of red wolves, which look similar to coyotes. At a public hearing in January 2015, a county commissioner depicted a battle against the environmental groups stating:

The issue doesn't begin with North Carolina Wildlife (Resources Commission) and U.S. Fish and Wildlife. The issue rests in the power that these non-governmental organizations, Defenders of Wildlife, all of those groups, that are used by the Southern Environmental Law Center, to bring suit after suit against our government.

J. Seaburg, a landowner contesting the RWRP and injunction, suggested the conflict prompted residents to violate federal wildlife law surmising, "I don't think (red wolves) got shot because they were mistaken as a coyote. Probably the coyote gettin' shot was a mistake." He then told the WRC, "You're just makin' outlaws out of good citizens." This is a reiteration of a point he made online (www.ncuntandfish.com-former home of the "Red Wolf Restoration Scandal" thread) in 2013 asserting that red wolf killings were perhaps violent acts of opposition to a pro-wolf agenda:

...these wolf killings may not be accidental. It is likely that the local citizens are just fed up with the Feds lying and imposing their wishes on us. Because our state and federal government will not listen to our concerns, they are probably fighting back in a way that only makes sense to them.

A sporting goods and firearms store owner in Engelhard, North Carolina alluded to citizen intentions to violate wildlife law: "I've heard it said many times, when they see them they're going to put a bullet in them because it's ruining what they enjoy doing" (B. Kenyon [Henderson, 2011]).

Threats from other hunters and landowners: Sociopolitical changes manifested shifts in societal hunting norms, resulting in clashes among hunters, and between hunters and landowners. These episodes threaten the existence of the rural hunting sub-culture in question. A growing body of politically influential leisure hunters and naturalists, the resurrection of game law, and the expanding readership of the American sporting press relegated hunting norms (e.g., hunting where and when one pleases, market hunting, and harvesting however many animals deemed necessary to feed the family) to unsportsmanlike standing (Proctor 2002). The imposition of outsiders' social norms threatens cultural meanings and aspects, such as social cohesion, identity, survival, that are fundamental to the rural hunting subculture. They may also provide a means for rural interests to distance themselves from larger society by continuing historical, but now outlawed, hunting practices (von Essen et al 2015). 
In North Carolina, tensions between dog hunters (those who hunt with dogs) and still hunters, and dog hunters and landowners who feel "disrespected" (female speaker, January 2015 hearing), have led to conflicting ideas about proper hunting style. Due to the free ranging nature of game and dogs, some dog hunters do not abide by private property laws. In sum, performing "taboo" hunting behaviors common to rural hunting sub-cultures (Brymer 1991, p.181]) were considered a major public relations problem that could impact the future of rural hunting practices, and hunting in general. These acts inspire "a bad reputation for other hunters that generally follow the laws and (who) want their kids to continue hunting" (Respondent 58, echoed by Respondent 45).

\section{Radicalization of a Hunting Subculture}

In this section we explain how the rural hunting subculture studied here has embarked upon a course towards radicalization due to engagement within a politics of the rural and historical mobilizations against sociopolitical changes. These phenomena have contributed to the marginalizing and ostracizing normative rural hunting practices and enhanced social cohesion within the hunting sub-culture. We employed McCauley and Moskalenko's (2008) radicalization framework as one way to articulate this trajectory. This framework is based on the following concepts: superiority, injustice, distrust, and vulnerability, which interact and influence each other (von Essen et al 2015).

Superiority: Superiority emerges as a step in radicalization of a sub-culture when a group begins to see itself as distinct from and superior to other groups, which can include wildlife (von Essen et al 2015). Hunting sub-cultures in industrialized societies tend to prioritize the needs of humans over animals (Teel and Manfredo 2010; von Essen et al 2015). In North Carolina, AP residents reinforced this notion when it came to the red wolf-coyote issue, stating to the WRC at a January 2015 rules hearing: "People come before coyotes and wolves, always." (J. Dixon) and "Are you protecting the red wolf's rights or the hunters' rights?" (S. Williams). We also found a hierarchy among wildlife species with hunters viewing game animals as superior to predators. Unpalatability of red wolf taxonomy and coyote non-nativeness were evidence of this finding in our data. For instance, a disgruntled landowner, resonating with other rural interests, disparaged the legitimacy of the red wolf as a species by equating it with the loathed coyote: "All we have here is a super coyote" (S. Little, September 2014 hearing). One informant summarized popular rural hunting sub-culture sentiment when commenting on the federal court ruling preventing citizens in five North Carolina counties from shooting coyotes at night: "You should be able to hunt coyote at night because it's not even supposed to be here" (Respondent 51).

The rural hunting subculture expressed that they were superior to other groups in several ways, but emphasized superior self-sufficiency, work ethic, resilience, and resourcefulness. Keefe (2000, p. 8) cited a twenty-year old firefighter who believed: "Mountain people know how 
to live off the land, know how to hunt and fish, know how to grow a garden." This was decoded within the broader context of Keefe's work to mean that mountain people have knowledge about survival that others do not. During a March 2015 WRC public hearing on coyote rules in Raleigh, an AP citizen echoed these sentiments and differentiated rural from urban citizens based on the lived experience with predators claiming:

We live off the land and we know how to conserve... but we're fighting a losing battle when you're dealing with animals that we eat... Who knows better than the people who live out in these rural counties? Whereas these people sittin' in Raleigh they'll never know what it is... at night...to hear 'em howl or (be afraid) to put (your) little dog out (S. Williams).

A second show of superiority was claiming that rural hunters were the real conservationists, a recurrent claim hunters make when they battle environmentalists. ${ }^{2}$ The county commissioner speaking at the January 2015 hearing distinguished rural peoples' ability to conserve wildlife from pro-red wolf and coyote environmental non-governmental organizations insisting, "I guarantee you there are better conservationists in this room than any one of those groups that have sued North Carolina or have sued the Department of Interior."

A third practice was highlighting a predisposition towards hunting behavior that make rural hunters feel superior to others. Hunting with dogs is a common but publically contentious rural hunting practice in most southeastern states. It is an integral part of rural heritage in the southeast, publically supported by the WRC, and deemed by many dog hunters to be a superior hunting practice to still hunting (Marks 1991). Southern hunters also denigrated other hunters' behavior in which they disapprove and rationalize their own illegal behavior (Brymer 1991; Marks 1991). For instance, informants who proclaimed they purportedly stumbled into an illegal take exhibited superiority over hunters that pursue it $^{3}$ by regarding the latter as "fucks" (Respondent 24) and "outlaws" (Respondent 42), such as those who hunted deer at night with spotlights ("jack lighting" — a legal practice in the U.K. and passé norm in the U.S.) - they were "the worst" (Respondent 31).

There is evidence that those within the hunting sub-culture see themselves as superior to urban people who are naïve about life and death and foodways. One AP resident declared that those within environmental groups, the opponents in the red wolf debate, were ignorant about organic foods. Superiority was implied because environmental groups' disputatious ways interfere with hunters' consumption of game. Another AP resident's commented, "They don't think that organic food comes from deer. They think it comes from Whole Foods. ${ }^{4}$ They don't see it as a food source for people nationwide...they see it as a good place to go to prevent people from hunting, in my opinion...it's a battle" (R. Bass). An AP landowner stated that "the other side" does not see the everyday realities of living with red wolves commenting: 
It's great to sit back in Seattle, Washington in your Subaru and say, "I've got a wolf sticker on the back of my truck. I love wolves." But, when they are eatin' everything that you've got on your farm and destroying your land, it's not that pretty" (S. Little).

Distrust: Lived experiences lead to beliefs about how the government does not care about a particular group or that the government cannot be trusted (McCauley and Moskalenko 2008). There is already general distrust of government in rural areas (Weisheit, Falcone, and Wells 2005), and history demonstrates that regulation of wildlife focused that mistrust on wildlife management and motivated illegal take. Informants linked lack of trust to complex and changing laws. Informants stated "they change laws, pretty much yearly on certain things" [Respondent 4]), and highlighted unsatisfactory means of communication (e.g., "replace the old (signs)" [Respondent 54]; and "a lot of their laws are not in their regulation book" [Respondent 4]).

Additionally, the USFWS's support for unwanted predator reintroduction, preventing hunting and recreation to protect a federally listed species, interfering with local livelihoods, and close working relationships with wildlife protection groups fostered a high degree of mistrust among rural people living on the AP, leading to beliefs about law-breaking, cover-ups, and conspiracies. Examples include: "The (USFWS) put the coyotes (there) to keep the wolves in their place" (unidentified speaker at 2015 public hearing); and causes of red wolf deaths are actually a "government cover-up" (odie408 [nchuntandfish.com] and "USFWS inside job" (BR549) [nchuntandfish.com]. The Wildlife Management Institute (WMI) (2014), an independent organization that chronicled issues with the RWRP (e.g., law breaking, failure to retrieve wolves) during their review of the program, noted an "atmosphere of distrust" among AP landowners. Several residents also felt the WRC "sold out" (C. Alberts, January 2015 hearing) hunters and landowners when the WRC agreed to the 2014 settlement conditions.

Distrust originating from this issue is also generated from the ongoing debate about a perceived decline in game populations. Some southern hunters seem to distrust state-collected data showing elevated annual deer harvests, forming a politically potent narrative about the toll canids have on game populations in the southeast. A speaker provided evidence for this idea asserting that animal rights activists were "registering deer they didn't kill just to up the (deer harvest) numbers" (C. Alberts, March 2015 hearing). Despite WRC data that suggests otherwise, a speaker at the January 2015 coyote rule hearings claimed: "We're running out of wildlife!"

Rural residents did not trust wildlife enforcement officers to make the right judgment when wildlife officers used their own discretion enforcing the law, and offenders distanced themselves from these officers. This was particularly true of those North Carolina enforcement officers displaying unpleasant demeanor (e.g., "mean"; "asshole"). Officer demeanor was linked to the occurrence of illegal behavior because it discouraged interaction between citizens and 
enforcement officers. One informant stated, "if (enforcement officers) need to apply judgment, and if they're always hard-nosed, then people are going to go around them. They don't trust them" (Respondent 2). Another stated that "harassment" by enforcement officers "causes people to rebel" (Respondent 48).

Vulnerability: Radicalization progresses further when a group believes it is facing extinction or decline (McCauley and Moskalenko 2008). Our analysis revealed the rural hunting sub-culture perceived decline or demise of historical identities and roles, lifestyles and practices, and heritage. For instance, as noted earlier, rural interests represented a special class of citizen who abided by wildlife use norms that ran counter to those of societal elites in the $19^{\text {th }}$ and $20^{\text {th }}$ centuries. In response to the encroaching elite ideology threatening the rural hunting subculture's survival, the sub-culture engaged "subdued resistance" (Montrie 2011, p. 47), continuing their desired hunting and fishing practices, defended their crops from predation, and harvested wildlife for markets even after wildlife laws were passed (Grigsby 2011; Brymer 1991). As the general subsistence public resisted controlled access to game, Elliott (1867, p.256258) described how hunters proclaimed "Hunters Law," the inalienable right to trespass, in order to frustrate the expanding private property rights movement and closure of the commons in the Carolinas. A timber company owner summarized the attitudes of those who continued to hunt his 40,000 acres in the Great Dismal Swamp post-purchase: 'Look, don't bother me about hunting. I hunted here, and my father and my sons, and we're gon' hunt here as long as we want to hunt here. You can forget trying to tell us what not to do," adding "they'd set your woods on fire" if he tried to prevent them from doing so (Kirby 2006, p.163).

More recently, in North Carolina, the law breaking habits of a few law violators are believed to threaten the existence of hunting, particularly dog hunting. Fighting for their heritage's survival, dog hunters employed negative external stereotypes to distinguished themselves from still-hunters (non-dog hunters) and society (Chitwood et al 2011). Their culture and identity is now defined to some degree by a narrative that negative societal perceptions about dog hunting stem from still-hunters' exaggerated and "pervasive" stereotypes that dog hunters choose to trespass onto private property and disturb still hunters (Chitwood et al 2011; Cook et al 2015).

There is a history of the rural hunting sub-culture fighting to protect their tradition of hunting for consumption out of necessity. For instance, Kirby (2006, p.258) wrote that "venison continued to be a staple meat" on the table of one Florida old-timer who refused to stop hunting despite his land becoming a game preserve. Though the need to rely on game for subsistence diminished during the southern agrarian and industrial revolutions, we found that hunting for consumption was a still widely practiced and considered essential within the rural hunting subculture. This was evident as informants displayed some semblance of hardship originating from a North Carolina political economy that has underserved rural citizens since the Civil War ended. Informants and public hearing speakers declared: "Some people I know, if they didn't hunt, they 
would have a hard time surviving without the meat because of their low income level" (Respondent 26); "I think in this economy the deer meat should have gone to the people, not wolves" (J. Dixon, January 2015 hearing); and "I keep a record every year of how much (venison) I put up in the freezer. I didn't put even a third of what I've been puttin' up because there's no deer to kill" (S. Williams, January 2015 hearing). Interview respondents generally approved of violating wildlife laws to feed oneself or kin as a response to this phenomenon. Respondent 16, a 52-year old male's perspective highlighted this finding:

I believe it's ok if you have fallen on hard times and you use it for subsistence. If it puts food on the table it is ok in my book. Everyone's gotta eat and if you can't buy groceries, kill something. That's the way we were all raised around here. It's been that way since I was little, and that's how my grandparents survived.

Further, several informants affirmed that they or others "weren't going to pay an outrageous amount of money" (Respondent 32) for permits that allow them to harvest deer meat and stock their freezers, and they "don't need any more" costly permits than what is already offered by the WRC (R. Wallace, speaker January 2015).

Injustice: Prioritization of goals that aren't their own, new laws, and mistreatment or betrayal can create a sense of injustice among a group (McCauley and Moskalenko 2008; von Essen et al 2015). When viewed as a sociopolitical crime, illegal behavior may emerge from injustices created by social structures that unintentionally or intentionally obstruct (Foucault 1979) rural people from hunting. Many of our informants attributed violations to poor fit between laws and the rural context. For instance, informants stated that wildlife laws were broken because people don't agree with them on the basis that the laws: "(don't) apply" (Respondent 27), are “stupid” (Respondent 2), “don't fit our area” (Respondent 15), “don't make sense" (Respondent 11), or contradict the way people were "raised" (Respondent 29) or how they "grew up" (Respondent 41). Landowner, L. Jamison spoke against the RWRP at a January 2015 coyote rules hearing saying: "You're five little rules here, they don't apply in all cases."

Many believed red wolf reintroduction goals were not in the best interest of the local population and were detrimental to rural community living. Citizens living in red wolf country blamed a synthetic, authoritative, and ill-fitting conservation program for their ills, such as living in fear of canids, as well as their nuisance and disruption of everyday life. A speaker summarized general complaints at the January 2015 hearing: "(The RWRP) has hurt our community and our people are not for it, so why is it being pushed on us?" (J. Dixon). Some speakers echoed contents in the WMI report (2014) stating they were ignored and lied to by USFWS, and what has transpired is a classic case of the federal government "overstepping its boundaries" (L. Bush, March 2015 hearing).

Ironically, given the fact that illegal take of wildlife in rural southeast emerged in large part from disenfranchising rural people from hunting through enforcement of property rights, 
perceptions of injustice against rural hunters now often hinge on insufficient property rights. This is a microcosm of a larger war over the privatization of wildlife enduring in the southeast since the $18^{\text {th }}$ Century (Proctor 2002). The concept of wildlife as a public resource does not apply to all offenders who observe the concept of property rights. There's a prevalent feeling that "it's their land and they don't have to (follow the law) (Respondent 56, echoed by Respondent 29, 33, and 47). When Respondent 11 was asked if he would break a deer regulation because he believed the deer on his property were his, he responded, "Yes." In the mid-1990s, a private landowner (convicted of slaying a red wolf and not reporting it within 24 hours) and other citizens founded a grassroots group called Citizens Rights Over Wolves Now (CROWN) to fight the RWRP. This group challenged the government's right to regulate activities on (i.e, take) private land, focusing on the ability to shoot red wolves (Bourne 1995). However, CROWN dissolved after two other citizens (including a second convicted of killing a red wolf and not reporting it within 24 hours) lost a 1998 federal lawsuit challenging prohibitions on private property to propagate red wolf recovery. More recently, landowners generally felt they were "unrepresented" in the settlement leading to the ban on night hunting coyotes on private property, while another speaker cited the politically radical intentions of outsiders that has led to negative property rights impacts for AP landowners at the March 2015 rules hearing,

I really don't think this is an issue about the red wolf at all. I believe this is unfortunately an issue of socialism and the issue of anti-hunting, and the agenda is basically to take away private, God-given, landowner rights...these rules are just coming in and raping us of our land and our time and our money (S. Little).

One resident stated the unjust coyote laws will be broken and that a code of silence will protect violators proclaiming, "It's gonna come to more shootin'... and don't say anything" (unidentified speaker, January 2015 hearing).

\section{Discussion}

Our investigation and North Carolina case hopefully serves as a heuristic means of stimulating further research on structural influences and their relationship to illegal take of wildlife among rural hunters in the southeastern U.S. Dominant societal cultural intrusions upon the southern rural hunting sub-culture's social institutions detached poor rural hunters from an urbanizing and industrializing society. This social split devalued game laws among the rural hunting subculture's members by tainting them with elite ideology. Our analysis of a sub-culture that customarily violates wildlife laws lends support for literature concluding such violations are socially and culturally patterned (Brymer 1991; Grigsby 2011). It also gives credence to studies that help contextualize the occurrence of hunting violations among marginalized and isolated groups by documenting how they devalue material and symbolic facets of the dominant culture and society, such as wildlife management regimes (von Essen 2014), animal rights, and trophy hunting (Forsyth et al 1998). 
This analysis supports the assertion that relationships between wildlife law and sociopolitical transformations are inherent to wildlife law violations. Therefore, in areas where the emergence of game laws stripped away temporal and spatial access to game primarily from the rural poor, for instance, regulators should not be surprised by illegal take activities. Moreover, in the southeastern U.S., the dominant narrative associated with the "North American Model" (Organ et al 2012) may help obfuscate the disenfranchisement and marginalization of rural hunters, as well as make illegal take a surprising and deplorable activity, seen as evidence that deviant behavior must be understood at the individual level through psychological measures. ${ }^{5}$ Our results also suggest structural changes resulting in authoritarian wildlife governance were associated with perceptions of injustice, vulnerability, superiority, and distrust among the rural hunting sub-culture studied. Consequently, the imposition of illegitimate wildlife law in rural parts of the southeastern U.S. appears to have nurtured the existence of an environment where illegally taking wildlife is generally accepted among the subculture, rendering it deviant. This particular idea has at least three implications for scholars and practitioners concerned with wildlife crime in the contemporary southeastern U.S.

First, our results contest the notion that it is feasible to accurately gauge the social acceptability of illegal take behavior in communities (Enck and Decker 1997). Because violating game law was closely associated with primary social networks in this study, it may be difficult for outsiders to ascertain the factual acceptability of illegal behavior when an uncle is covering for a nephew, a neighbor is covering for a neighbor. This assertion is supported by the crime and social networks literature revealing that law breaking is influenced by the cascading effects of larger structural forces, such as political economy, on the formation of behavior-reinforcing primary social networks that may include entire communities. Papachristos (2012, p.398) noted:

...individuals are more likely to break the law when they live in neighborhoods bereft of social, economic, and human capital, when their social networks are saturated with criminal peers and opportunities, and when they are socialized into dense delinquent networks that do not fully admonish deviant behaviors.

Accordingly, we also question the idea that this sub-culture will openly discuss violations with outsiders (e.g., inquisitive academics), or report them to wildlife enforcement officers who tend to rely on snitching to catch lawbreakers (Eliason 2003a). Second, by highlighting the politics of place we observed that sociopolitical factors create contested meanings of illegal take, as well as contribute to delegitimization of wildlife law (von Essen et al 2015). Trust and legitimacy are required to increase voluntary compliance with wildlife and other conservation laws (Kahler and Gore 2012), but are likely diminished when self-expression is also limited (Boateng 2014). Effective discursive engagement with subculture gatekeepers may be one way to address concerns about exclusivity in wildlife governance and ascribed to classic decision 
making paths, such as winner take all ballot initiatives, lawsuits (Jacobson and Decker 2006), and one-sided tactical communication (Boateng 2014). Employing discursive engagement, four processes - appreciating individual and contextual differences; sharing experiences; engaging critical self-reflection; and building alliances (Nagda 2006) — must be considered by wildlife decision makers to foster positive governance transformation in the arena of illegal take, and further research will need to explore the conditions in which these processes initiate, succeed, and fail. Finally, should the broader sociopolitical context dramatically shift once again, negatively impacting the rural hunting subculture as it has periodically for centuries, it is reasonable to assume that illegal take of wildlife will rise in rural places because survival still trumps wildlife law (Lund 1951).

Examining illegal hunting in the southeastern U.S. through a radicalization lens suggests a need to explore the notion that a hunting counterpublic exists in the region. A counterpublic in this instance may be formed by responding to: a) wildlife conservation authorities and external agendas that offer no room for alternative subjectivities and ecosocial imaginaries; $b$ ) government wildlife agencies that do not exhibit reasonable nor agreeable decision making; and c) illegitimate external policies and ideals (Eckert and Chadha 2013). What is notable about this potential counterpublic is that its contemporary narrative encompasses a politically powerful discourse that devalues invasive lives (coyotes) in rural areas through ethical, as well as biocentric, justifications (Carruthers et al 2011). It is a discourse that is ironically shared between the counterpublic and a growing portion of a southern society that does not exactly discourage the illegal hunting of coyotes (e.g., a class II misdemeanor carrying a USD\$10 fine, with no replacement cost or mandatory court appearance in North Carolina; publically placing much blame on the coyote for white-tailed deer [Odocoileus virginianus] population declines in South Carolina as the Department of Natural Resources asked hunters to: "Help control coyotes, save our deer!"). Perhaps, coopting political discourses, such as the elimination of non-native species or illegitimacy of species taxonomy ${ }^{6}$, is one way counterpublics are able to create a pluralistic political space for their rationalities to be discussed and debated (von Essen 2015).

Shifting sociopolitical contours that stimulate illegal take behavior make it difficult for wildlife agencies to motivate a deviant rural hunting sub-culture to comply with wildlife laws through their standard operating procedures (rule promulgation, enforcement, and education/outreach). Deliberate law violations originating from a politics of the rural are integral to the rural hunting sub-culture and wildlife agencies may intensify illegal behavior through purposive or inadvertent exclusionary policies and practices. This may explain why the linear knowledge-attitude-behavior approach to predicting and influencing stakeholders, which wildlife and other resource management agencies count on to boost voluntary wildlife-related compliance, does not always stand up to empirical testing (Kahler and Gore 2012). Further, sociopolitical shifts have fragmented the broader rural hunting subculture (Woods 2006, p. 592) in the southeast over the last 200 years, complicating efforts to understand illegal hunting. Different factions of this sub-culture, including the one studied here, have different norms, 
networks, and identities surrounding wildlife-related compliance. A politics of the rural is as much about struggles within the array of hunting sub-cultures as it is about a struggle by a deviant sub-culture against external threats; it provides an innovative and compulsory framing with which to study and address illegal take behavior. 


\section{Endnotes}

${ }^{1}$ These laws pertain to raising livestock.

${ }^{2}$ This belief has been expressed by celebrity hunters, such as Ted Nugent and Sarah Palin, as well as common hunters, in various outlets online (e.g., newspapers, Facebook, blogs) and easily found.

${ }^{3}$ Inadvertent illegal take was demonstrated in our informant interviews with regularity and at a January coyote rules hearing in Columbia, NC. An unidentified speaker provided an example: “....say that wolf with a collar's...comin' to ya, to a call, you're gonna shoot it thinkin' it's a coyote. You're not gonna see that collar, regardless."

${ }^{4}$ A North American supermarket specializing in organic food.

${ }^{5}$ Somewhat ironically, and given the ontology of this approach to wildlife conservation in North America, descriptions of the model often tout it as catering specifically to the masses rather than social elites (Geist, Mahoney, and Organ 2001).

${ }^{6}$ For an example, see the NCWRC resolution passed in January of 2015 declaring the red wolf extinct in the wild: http://www.ncwildlife.org/Portals/0/About/documents/2015-01-29-NCWRCResolution-Asking-USFWS-Declare-Red-Wolf-Extinct-in-Wild-Terminate-Program.pdf 


\section{References}

Altrichter, H., Feldman, A., Posch,, P., and Somekh, B. (2013). Teachers investigate their work; An introduction to action research across the professions $\left(2^{\text {nd }} \mathrm{Ed}\right)$. New York: Routledge.

Bell, S., Hampshire, K., and Topalidou, S. (2007). The political culture of poaching: A case study from northern Greece. Biodiversity and conservation, 16, 399-418, http://dx.doi.org/10.1007/s10531-005-3371-y

Boateng, W. (2014). Social integration and conflict prevention: The role of discursive engagement. International Affairs and Global Strategy, 25, 59-64.

Bourne, J. (1995), Hyde County's wolf war, Defenders, 70, 10-17.

Brymer, R. A. (1991). The emergence and maintenance of a deviant sub-culture: The case of hunting/poaching sub-culture. Anthropologica, 33, 177-194, http://dx.doi.org/10.2307/25605608

Chazkel, A., and Serlin, D. (2010). Enclosures: Fences, walls, and contested spaces: Editors' Introduction. Radical History Review, 2010, 1-10, http://dx.doi.org/10.1215/016365452010-001

Chitwood, M.C., Peterson, M.N., and Deperno, C.S. (2011). Assessing dog hunter identity in coastal North Carolina. Human Dimensions of Wildlife, 16, 128-141, http://dx.doi.org/10.1080/10871209.2011.551448

Coclanis, P. A., and Kyriakoudes, L.M. (2007). Selling which south? Economic change in rural and small-town North Carolina in an era of globalization, 1940-2007. Southern Cultures, $13,86-102$.

Cook, M.A., Peterson, M.N., Chitwood, M.C., Palmer, D., DePerno, C.S., and Gross, K. (2015). Evaluating deer hunters' support for hunting deer with dogs. Human Dimensions of Wildlife, 20, 174-181, http://dx.doi.org/10.1080/10871209.2014.997328

Eckert, S., and Chadha, C.K. (2013). Muslim bloggers in Germany: An emerging counterpublic. Media, Culture \& Society, 35, 926-942, http://dx.doi.org/10.1177/0163443713501930

Eliason, S.L. (2011). Patrolling the peaks and the plains: An examination of Big Sky game wardens. Criminal Justice Studies, 24, 409-418, http://dx.doi.org/10.1080/1478601X.2011.626153

Eliason, S.L. (2003a). Throwing the book versus cutting some slack: Factors influencing the use of discretion by game wardens in Kentucky. Deviant Behavior 24, 129-152, http://dx.doi.org/10.1080/01639620390117219

Eliason, S.L. (2003b). Illegal hunting and angling: The neutralization of wildlife law violations. Society \& Animals, 11, 225-243, http://dx.doi.org/10.1163/156853003322773032 
Eliason, S.L. (1999). The illegal taking of wildlife: Toward a theoretical understanding of poaching. Human Dimensions of Wildlife, 4, 27-39, http://dx.doi.org/10.1080/10871209909359149

Enck, J.W., and Decker, D.J. (1997). Examining assumptions in wildlife management: A contribution of human dimensions inquiry. Human Dimensions of Wildlife, 2, 56-72, http://dx.doi.org/10.1080/10871209709359102

Flowers, L. (1992). Throwed away: failures of progress in eastern North Carolina. Knoxville: University of Tennessee Press.

Flynt, W. (2004). Dixie's forgotten people: the South's poor whites. Bloomington: Indiana University Press.

Ford, A. M. (1973). Political economics of rural poverty in the South. Cambridge, MA: Ballinger Publishing

Forsyth, C. J., Gramling, R., and Wooddell, G. (1998). The game of poaching: Folk crimes in southwest Louisiana. Society \& Natural Resources, 11, 25-38.

Foucault. M. 1979. Discipline and punish: The birth of the prison. New York: Vintage Books.

Gavin, M. C., Solomon, J.N., and Blank, S.G. (2010). Measuring and monitoring illegal use of natural resources. Conservation Biology, 24, 89-100, http://dx.doi.org/10.1111/j.15231739.2009.01387.x

Geist, V., Mahoney, S.P., and Organ, J.F. (2001). Why hunting has defined the North American model of wildlife conservation. Transactions of the North American Wildlife and Natural Resources Conference 66, 175-185.

Giltner, S. E. (2010). Hunting and fishing in the new South: Black labor and white leisure after the Civil War. Baltimore, MD: Johns Hopkins University Press.

Grigsby, M. (2011). Subcultural masculine moral identity work among rural Missouri noodlers: A special breed of men. Anthropologica, 53, 159-171.

Guba, E.G., and Lincoln, Y.S. 1985. Naturalistic inquiry. Beverly Hills, CA: SAGE.

Henderson, B. (July 11, 2010). NC: Rare species faces growing threat Red wolf repopulation effort in northeastern N.C. at risk. BlueRidgeNow.com. Retrieved from http://www.blueridgenow.com/article/20100711/news/100719973

Kahler, J. S., and Gore, M.L. (2012). Beyond the cooking pot and pocket book: Factors influencing noncompliance with wildlife poaching rules. International Journal of Comparative and Applied Criminal Justice, 36, 103-120, http://dx.doi.org/10.1080/01924036.2012.669913 
Kirby, J. T. (2006). Mockingbird song: Ecological landscapes of the South. Chapel Hill: University of North Carolina Press.

Lund, T. A. (1976). Early American wildlife law. NYU Law Review, 51, 703-730.

Marks, S. A. (1991). Southern hunting in black and white: Nature, history, and ritual in a Carolina community. Princeton, NJ: Princeton University Press.

Mell, M. R. (1938). Poor whites of the South. Social Forces, 17, 153-167, http://dx.doi.org/10.2307/2570919

Montrie, C. (2011). A people's history of environmentalism in the United States. New York: Continuum International Publishing.

Muth, R. M., and Bowe, J.F. (1998). Illegal harvest of renewable natural resources in North America: Toward a typology of the motivations for poaching. Society \& Natural Resources, 11, 9-24, http://dx.doi.org/10.1080/08941929809381058

Nagda, B. A. (2006). Breaking barriers, crossing boundaries, building bridges: communication processes in intergroup dialogues. Journal of Social Issues, 62, 553-576, http://dx.doi.org/10.1111/j.1540-4560.2006.00473.x

Organ, J. F., Geist, V., Mahoney, S.P., Williams, P., Krausman, P.R., Batcheller, G.R., and Decker, D.J.. (2012). The North American model of wildlife conservation. Technical Review 12-04. Bethesda, MD: The Wildlife Society.

Papachritos, A.V., Meares, T.L., and Fagan, J. (2012). Why do criminals obey the law-the influence of legitimacy and social networks on active gun offenders. Journal of Criminal Law and Criminology, 102, 397-440.

Peterson, M.N., Peterson, T.R., Peterson, M.J., Lopez, R.R., and Silvy, N.J. (2002). Cultural conflict and the endangered Florida Key deer. The Journal of Wildlife Management, 66, 947-968, http://dx.doi.org/10.2307/3802928

Petty, A. M. (2013). Standing their ground: Small farmers in North Carolina since the Civil War. New York: Oxford University Press, http://dx.doi.org/10.1093/acprof:oso/9780199938520.001.0001

Pitcher, T., Watson, R., Forrest, R., Valtýsson, H. P. and Guénette, S. (2002). Estimating illegal and unreported catches from marine ecosystems: A basis for change. Fish and Fisheries, 3, 317-339, http://dx.doi.org/10.1046/j.1467-2979.2002.00093.x

Proctor, N. W. (2002). Bathed in blood: Hunting and mastery in the old South. Charlottesville: University of Virginia Press.

Reeves, S., Kuper, A. and Hodges, B.D. (2008). Qualitative research methodologies: Ethnography. BMJ, 337, 512-514, http://dx.doi.org/10.1136/bmj.a1020 
Roebuck, J. and Hickson, M. III. 1982. The southern redneck: A phenomenological class study. New York: Praeger.

Teel, T.L. and Manfredo, M.J. (2010). Understanding the diversity of public interests in wildlife conservation. Conservation Biology, 24, 128-139.

von Essen, E., and Allen, M.P. (2015). Reconsidering illegal hunting as a crime of dissent: Implication for justice and deliberative uptake. Criminal Law and Philosophy, 21, 1-16; http://dx.doi.org/10.1007/s11572-014-9364-8.

von Essen, E., Hansen, H.P., Källström, H.N., Peterson, M.N., Peterson, T.R. (2014).

Deconstructing the poaching phenomenon: A review of typologies for understanding illegal hunting. British Journal of Criminology, 54, 632-651, http://dx.doi.org/10.1093/bjc/azu022

Weisheit, R.A., Falcone, D.N., and Wells, L.E. (2005). Crime and policing in rural and smalltown America. Long Grove, IL: Waveland Press.

Wildlife Management Institute, Inc. (WMI). (2014). A comprehensive review and evaluation of the red wolf (Canis rufus) recovery program. Gardners, PA: S. Williams, Williamson, S., Smith, C., \& Gassett, J. 